\title{
A Users' Satisfaction on the Environmental Performance of Naturally Ventilated Library: A Structural Equation Modeling Approach
}

\author{
El-Nafaty Abbas Said ${ }^{1,2}{ }^{*}$, Mohd Hamdan Ahmad ${ }^{1,3}$, Malsiah Hamid ${ }^{1}$ \\ and Wallace Imoudu Enegbuma ${ }^{4}$ \\ 'Department of Architecture, Faculty of Built Environment, \\ Universiti Teknologi Malaysia, Skudai - 81310, Johor, Malaysia; malsiah.hamid@gmail.com \\ 2Department of Architecture, Faculty of Environmental Science, \\ Abubakar Tafawa Balewa University Bauchi (ATBU), Nigeria; elnafatyabbas@gmail.com \\ ${ }^{3}$ Institute Sultan Iskandar, Universiti Teknologi Malaysia, Skudai - 81310, Johor, Malaysia; b-medan@gmail.com \\ ${ }^{4}$ Department of Civil Engineering, Faculty of Engineering, Computing and Science, \\ Swinburne University of Technology, Kuching - 93350, Sarawak, Malaysia; wenegbuma@swinburne.edu.my
}

\begin{abstract}
Objective: Library users beside been under duress of the inherent academic challenges are also faced with acclimatizing to the environment around them. The paradigm shift in environmental satisfaction research pits users against the dynamic nature of the environment. Hence, this paper directs the need for adequate post-occupancy analysis to address this trend. Methods/Statistical Analysis: A total of 514 questionnaires were derived from 4 respective libraries in Northeastern Nigeria. Descriptive and Structural Equation Modeling (SEM) analysis were carried out with SPSS and AMOS v22. Findings: The results revealed that the variables exhibited high correlation among each other. Ventilation Satisfaction had the highest impact on environmental satisfaction while acoustic had the lowest impact on environmental satisfaction. Applications/Improvements: Recommendations on policies were given to improve Acoustics within the Libraries.
\end{abstract}

Keywords: Library, Nigeria, Performance, Structural Equation Modeling, Questionnaire Survey, User Satisfaction

\section{Introduction}

Offices and managers of facilities are constantly faced with the challenges of addressing the pressure of allocation of spaces to staffs and users in a floor plan to reduce overall cost on the establishment. However, reduction in spaces for each individual, groups or functions leads to high risk of creation of unpleasant working environment to carry out functions effectively. The adverse environmental conditions produced are increased noise, obstruction of air circulation and lighting which invariably leads to hindrance on privacy and increased work stress ${ }^{1}$. Indoor Environmental Quality (IEQ) varies from location to location in higher education facilities ${ }^{2}$. Due to high demand in balancing energy consumption towards a sustainable energy, higher education facilities are constantly faced with challenges of monitoring facilities to comply with international standards $\frac{2,3}{3}$. The paradigm shift in rating systems of Leadership in Energy and Environmental Design (LEED) and Building Research Establishment Environmental Assessment Method (BREEAM) has led to an increase in standardizing IEQ to improve library user satisfaction 2 . Minimizing the effects of indoor pollutants is a priority in building design as Americans spend on average $90 \%$ of their time indoors where the Environmental Protection Agency (EPA) reports those levels of pollutants may run two to five times and occasionally more than 100 times higher than outdoor levels4.

${ }^{*}$ Author for correspondence 
Currently, limited information exists on perception on ventilation, acoustic and visual satisfactions for environmental satisfaction ${ }^{5}$. Constructor sector for more sustainability will be improved by overcoming the inertia to adopt new techniques towards sustainability ${ }^{6}$. Hence, this paper aims to examine the user perception of ventilation, acoustic and visual satisfaction from naturally ventilated libraries.

\subsection{Indoor Environmental Satisfaction}

Characteristics of the individuals occupying a building, building type and control indoor environment and external climate condition affect user comfort, factors such as ventilation, acoustic and visual are also pivotal to user satisfaction in libraries ${ }^{7}$. Statistically significant difference were found between user satisfaction in green building and conventional building for building performance in acoustics, lighting and thermal conditions except for lighting3. User prefer natural window opening for fresh air supply than mechanical ventilation ${ }^{8}$. Similarly, user overlook such discomfort of ventilation without resulting to finding solutions to the problem of inadequate ventilation8. Close proximity to windows increase environmental satisfaction which decreases as distance increases away from the window opening? Acoustic satisfaction was found to be higher in single office space and then shared offices and lowest in cubicles $^{9}$. Hierarchical space allocation to users within a building envelope has a direct influence on the users visual satisfaction ${ }^{?}$.

In a study on environmental satisfaction in open plan spaces, privacy, lighting and ventilation were found to be the overriding variables affecting user satisfaction 1 . Privacy assessed "visual privacy, conversational privacy, amount of noise from others' conversations, amount of background noise; amount of distraction, workstation size, degree of enclosure, ability to alter conditions; distance between coworkers; and aesthetic appearance". Lighting assessed "lighting quality, quantity of light on the desk, quantity of light for computer work, computer glare, and access to a view". Ventilation assessed "lighting quality, quantity of light on the desk, quantity of light for computer work, computer glare, and access to a view" ${ }^{\prime}$. The study found that there exist an inter-correlations between privacy, lighting and ventilation on environmental satisfaction, direct relationships between privacy, lighting and ventilation on overall environmen- tal satisfaction, and a direct relationship between overall environmental satisfaction and job satisfaction while the relationships were all significant ${ }^{1}$.

In classroom settings, day lighting effect student performance on math tests by $20 \%$ and reading tests by $26 \% 10$. Similarly, good views increases student learning whereas glare, direct sun penetration, poor ventilation and poor indoor air quality decrease the students learning abilities11. Studying in classrooms with natural daylight reduced the absenteeism 3.5 days per year compared to little day lighting classrooms ${ }^{12}$. Student, teacher and staff absenteeism in green Canadian schools improved by $2-7.5 \%$, whereas student performance improved by $8-19 \%$ when compared with conventional schools $\frac{13}{}$.

Workers prescribe importance in quality of the overall building in order to discharge their duties in a balanced psychological well-being ${ }^{14}$. Improvement in indoor air quality (IAQ) would increase worker satisfaction with the overall building quality. IAQ and thermal comfort are directly associated with worker productivity and health issues in the workplace. "Since the cost of employees in doing business is substantially higher than the cost of energy, workplace designers need to provide workers an environment as comfortable and productive as possible through improved IAQ and thermal comfort $\frac{15}{}$. Building age has a correlation with level of satisfaction of users with IEQ and there is needs to constantly monitor and improve indoor environmental conditions 2 . Improvements in IEQ performance could be costly but help in reducing absenteeism and increase the productivity of students, staff, and faculty at higher educational facilities 2 . Having discussed the various dimensions of ventilation, acoustic and visual satisfaction, Figure 1 highlights the conceptual model of this study.

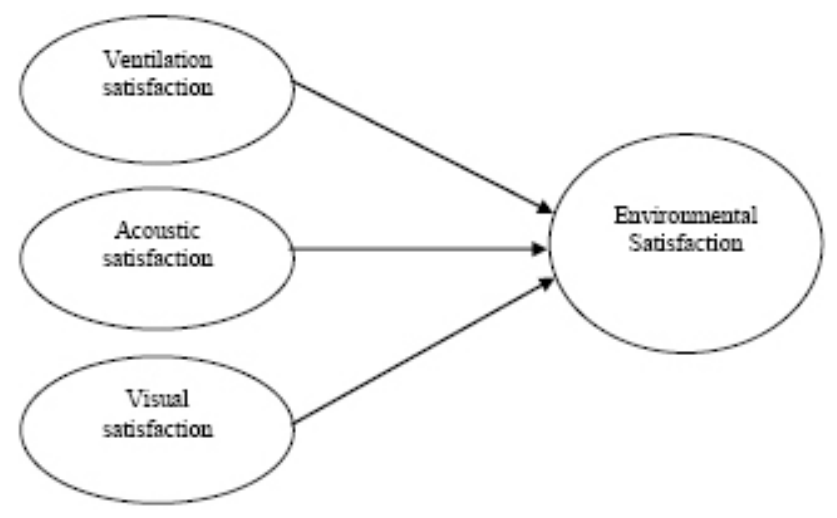

Figure 1. Environmental satisfaction conceptual model. 


\section{Methodologies}

Case study method approach and Post Occupancy Evaluation (POE) survey method was employed in conducting the research focusing on four naturally ventilated library buildings of different occupant sizes and building types within academic buildings in the University; Abubakar Tafawa Balewa University (ATBU) Library, Polytechnics; Muhd Wabi Library and Abubakar Tatari Ali Library Polytechnic (ATAP) library and collages of education: Collage of Agriculture (CA) Library, Yelwa all the selected libraries were funded and managed by the government in Bauchi (10 18' 57" North, 9 ${ }^{\circ}$ 50' 39" East) Nigeria. Mohd Wabi Library and ATAP library have been operating for over 20 years without any air-conditioning installed in the buildings, while ATBU and CAL have but few window units and split unit $\mathrm{AC}$ which have not been functioning as a result of interrupted power supply experienced in the country. Nigeria with a population of over 177.5 million people (World bank, 2014) is yet to generate and transmit more than $4000 \mathrm{MW}$ of electricity with only $40 \%$ of the population having access to electricity (Aliyu et al, 2013) as such the most reliable ventilation system remains natural ventilation. All the library building designs were based on natural ventilation principle. Table 1 shows the case study buildings. According to Creswell,
2012 survey research method expedites collection of reliable data from a specific population. Nicol et al, 2012; Leaman and Bordass, 2010, also posited that people are the best instrument for measuring environmental performance and added that they are only arduous to calibrate due to differences of adaptation and biological make-up. The assessment of Users' satisfaction toward their reading halls was measured using questionnaire in order to get a feedback on the impact of IEQ in the building typology. The empirical data was collected in the month of May, June, July and August in 2014.

The questionnaire was adapted from Cost-Effective Open-Plan (COPE) field study, for the study of Environmental Satisfaction in Open-plan Environments conducted by $\frac{1}{}$ developed originally. The original instrument contains 18-item a of Environmental Feature Ratings (EFR) which was reduced to 17-item for the present study focusing on the environmental condition items only. A seven-point Likert scale was used to ask the respondents to rate their satisfaction based on the ambient environmental conditions relating to the internal environment of the buildings.

Data preparation and screening was conducted using the procedures recommended by ${ }^{16}$. Univariate normality was assessed by examining the kurtosis and skewness values of the individual items. According to ${ }^{\frac{16,17}{2}}$ " skewness

Table 1. Case study buildings

\begin{tabular}{|c|c|c|c|c|c|c|}
\hline No & $\begin{array}{l}\text { Building } \\
\text { Codes }\end{array}$ & $\begin{array}{c}\text { Pictures/ Orientation } \\
\text { (long side)* }\end{array}$ & Capacity & $\begin{array}{c}\text { Ventilation } \\
\text { mode }\end{array}$ & $\begin{array}{c}\text { Building } \\
\text { type }\end{array}$ & $\begin{array}{c}\text { Year } \\
\text { constructed }\end{array}$ \\
\hline B1 & $\begin{array}{l}\text { University Library } \\
\text { Building (ULB) }\end{array}$ & & 1200 & $\begin{array}{c}\text { Natural } \\
\text { ventilation } \\
\text { with few AC in } \\
\text { some areas }\end{array}$ & $\begin{array}{l}\text { Multi } \\
\text { storey }\end{array}$ & 1992 \\
\hline $\mathrm{B} 2$ & $\begin{array}{c}\text { Mohd Wabi library } \\
\text { (FLB) }\end{array}$ & NE-SW & 500 & $\begin{array}{l}\text { Natural } \\
\text { ventilation } \\
\text { Zero AC }\end{array}$ & $\begin{array}{l}\text { Multi } \\
\text { storey }\end{array}$ & 1996 \\
\hline B3 & $\begin{array}{l}\text { ATAP library } \\
\text { SPL }\end{array}$ & N-S & 330 & $\begin{array}{c}\text { Natural } \\
\text { ventilation } \\
\text { Zero AC }\end{array}$ & $\begin{array}{l}\text { Single } \\
\text { storey }\end{array}$ & 1983 \\
\hline B4 & $\begin{array}{l}\text { College of } \\
\text { Agriculture } \\
\text { (CAL) }\end{array}$ & ES-SW & 120 & $\begin{array}{c}\text { Natural } \\
\text { ventilation }\end{array}$ & $\begin{array}{l}\text { Single } \\
\text { storey }\end{array}$ & 1990 \\
\hline
\end{tabular}


values greater than an absolute value of 3 and kurtosis values greater than an absolute value of 8 indicate univariate normality problems. Univariate outliers were identified by examining frequency distributions of standardized scores and multivariate outliers were detected by examining the values of the Mahalonobis distance statistic. Spot checks of several scatter plots indicated the presence of bivariate normality and linearity. Multivariate normality was assessed by examining the probability plot for each variable. Correlation matrices were examined to check for multi-collinearity and singularity (these terms refer to circumstances in which variables are very highly correlated, so that understanding their separate relations to other variables is impossible)"

Exploratory Factor Analysis (EFA) was conducted on the 514 empirical data to identify the theoretical underlying variables after data descriptive and cleaning using procedure recommended by ${ }^{16}$. Confirmatory Factor Analysis (CFA) was carried out to test or modify the model relationships between the latent variable identified in EFA and observed variables. Structural Equation Modeling (SEM) was finally done to test the overall coefficient of the regression and correlation of the fit model. The fitness indices in CFA and SEM include the Absolute fit (Chi square $\left(\chi^{2}\right)$, RMSEA and GFI), incremental fit (AGFI, CFI, TLI and NFI) and Parsimonious fit (Chi square by degree of freedom $\left(\chi^{2} / d f\right)$ respectively ${ }^{17-19}$.

\section{Results and Discussion}

Table 2 shows the average values of satisfaction levels for the items in the questionnaire with EFR10 (satisfaction with air movement) as the highest mean and EFR11 (satisfaction with distance between you and window) with mean of 5.25, the table also shows standard deviations, Skewness and kurtosis for the univariate analysis from the empirical data.

Multi-collinearity and singularity were also tested on the screened data. Exploratory factor analysis was used to identify the existence of theoretical latent or underlying variables $1,17,20,21$. This is a statistical technique that examines the inter-correlations between scores that individuals provide on individual questions, seeking a simple structure of interpretable underlying variables that might explain the inter0-correlations. Using the factor analysis procedure in SPSS (maximum likelihood extraction and varimax rotation) a free EFA was conducted to determine the number of factors. The cutoff for factor loadings to be included in a factor was 0.4. This resulted in a solution with four factors having Eigen values greater than 1 (range $=1.29$ to 5.45). The four-factor solution was composed of four clear factors (ventilation, acoustic, visual, and privacy satisfaction) with several high value loading items on each.

The measurement model shows the correlations strength among the constructs for this paper. The minimum thresholds of indices used in measuring measurement model fit are stipulated by previous researchers which are $\mathrm{p}<0.05, \chi 2 / \mathrm{df} \leq 2-5, \mathrm{RMR}<0.06, \mathrm{CFI} \geq 0.90$, GFI $\geq 0.90$ and RMSEA $\leq 0.05-0.80^{17,19,21}$. The statistics shown in the measurement model revealed an RMSEA value at 0.41 , CFI at 0.973 and close to a perfect fit and CMIN of 2.277. The fit statistics are adequate within the acceptable thresholds and factor loadings to establish convergence validity of the environmental satisfaction.

The structural equation model in Figure 2 and resulting path test of two-tailed significance in Table 3, 4 revealed several noteworthy findings. Out of the three (3) variables measuring perceived environmental satisfaction, ventilation satisfaction had the highest significant impact of 0.39 on environmental satisfaction. This findings are consistent with previous research $\frac{2,7,13-15}{}$ which suggests that in this study, library users in this libraries prefer ventilation as an overriding factor to their environmental satisfaction when compared to other factors. Hence, in designing and making decisions for improvement in the building design, ventilation needs to be of top most priority for effective user satisfaction. Visual satisfaction had the second highest significant impact on environmental satisfaction which is consistent with previous research $\frac{3,11-13,22}{}$. Although visual satisfaction was not as high as ventilation, this factor revealed to be sufficiently important by the library users in this study.

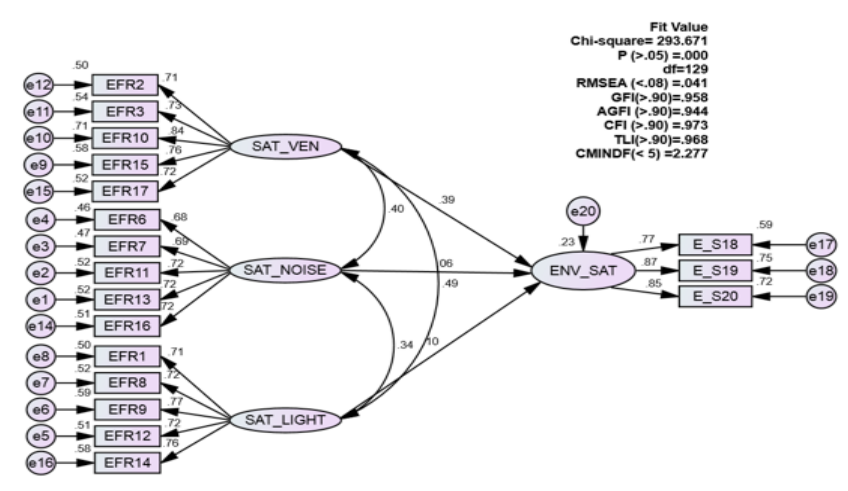

Figure 2. Environmental satisfaction structural equation model. 
Table 2. Descriptive statistics

\begin{tabular}{|c|c|c|c|c|}
\hline Question & Mean & SD & Skewness & Kurtosis \\
\hline EFR 1. Amount of natural lighting & 5.44 & 1.000 & -0.652 & 0.400 \\
\hline EFR 2. Air quality in the building & 5.69 & 0.920 & -0.633 & 0.354 \\
\hline EFR 3. Temperature in the building & 5.63 & 0.890 & -0.740 & 0.937 \\
\hline EFR 4. Level of privacy for conversations & 5.47 & 0.890 & -0.600 & 0.812 \\
\hline EFR 5. Level of visual privacy & 5.78 & 0.760 & -0.570 & 0.552 \\
\hline EFR 6. Amount of noise from inside & 5.40 & 1.110 & -0.651 & 0.205 \\
\hline EFR 7. Amount of background noise (i.e. not speech) & 5.40 & 1.070 & -0.635 & 0.242 \\
\hline EFR 8. Amount of glare from sun & 5.39 & 1.040 & -0.718 & 0.599 \\
\hline EFR 9. Amount of artificial light or glare in the fixtures & 5.35 & 1.080 & -0.749 & 0.582 \\
\hline EFR10. Overall Air movement in the building & 5.92 & 0.720 & -0.468 & 0.828 \\
\hline EFR11. Distance between you and window & 5.25 & 1.110 & -0.510 & 0.121 \\
\hline EFR12. Quality of lighting in the building & 5.58 & 0.860 & -0.642 & 0.899 \\
\hline EFR13. Frequency of distractions from other people & 5.62 & 0.980 & -0.641 & 0.439 \\
\hline EFR14. Overall visual comfort & 5.41 & 1.020 & -0.836 & 0.584 \\
\hline EFR15. Overall noise quality & 5.77 & 0.710 & -0.306 & 0.821 \\
\hline EFR16. Overall thermal comfort & 5.56 & 1.130 & -0.907 & 0.666 \\
\hline EFR17. Amount of humidity in the building & 5.68 & 0.950 & -0.711 & 0.531 \\
\hline ES_18.Overall comfort & 5.25 & 0.951 & -0.432 & 0.590 \\
\hline ES_19.Productivity & 5.40 & 0.948 & -0.747 & 0.943 \\
\hline ES_20.Health and wellbeing & 5.39 & 0.937 & -0.738 & 0.933 \\
\hline
\end{tabular}

Table 3. Test of hypotheses

\begin{tabular}{|l|c|c|c|c|c|c|c|}
\hline \multicolumn{3}{|c|}{ Variables } & Estimate & S.E. & C.R. & P & Remark \\
\hline Environ. Satisfaction & $<---$ & Vent. Satisfaction & .390 & .068 & 7.822 & $* * *$ & Significant \\
\hline Environ. Satisfaction & $<---$ & Acoustic Satisfaction & .062 & .046 & 1.362 & .173 & Insignificant \\
\hline Environ. Satisfaction & $<---$ & Visual Satisfaction & .103 & .055 & 2.234 & .025 & Significant \\
\hline
\end{tabular}

This factor is worth considering in future renovation and improvement in the building design. The results implies the users perceive that the amount of glare from sun, amount of artificial light or glare in the fixtures, amount of natural lighting and the quality of lighting in the building affect their environmental satisfaction. Acoustic satisfaction had an insignificant impact of 0.06 on environmental satisfaction in this study which is contrary to findings in previous study ${ }^{1,3}$. This suggests that irrespective of the distance between users and window, amount of background noise, amount of surrounding noise and frequency of distractions from other people, the users still considered this condition comfortable for them in carrying out their various activities within the library.

\section{Conclusion}

The study set out to examine the effects of ventilation, acoustics and visual comfort on indoor environmental satisfaction. This was achieved through the perception responses from library users. Ventilation Satisfaction was statistically significant and had the highest effect on environmental satisfaction while Visual satisfaction too was significant at $\mathrm{p}=0 \mathbf{2 5}$. Both ventilation and visual satisfaction have an effect of 0.39 .and, 0.10 respectively. However, Acoustic Satisfaction was insignificant but had effect of 0.06. This study explicates the significant impact of ventilation, acoustics and visual comfort on indoor environmental satisfaction towards improving the building environment for both students and staff library users. The 
findings imply that the quality of the indoor environment can be improved by addressing the needs of the occupants. Future IEQ policies will be improved by taking into account the findings of this paper towards improving IEQ for library users.

\section{References}

1. Veitch JA, Farley KMJ, Newsham GR. Environmental satisfaction in open-plan environments. Scale Validation and Methods. 2002:1-26.

2. El Asmar M, Chokor A, Srour I. Are building occupants satisfied with indoor environmental quality of higher education facilities? Energy Procedia. 2014; 50(480):751-60.

3. Liang HH, Chen CP, Hwang RL, Shih WM, Lo SC, Liao HY. Satisfaction of occupants toward indoor environment quality of certified green office buildings in Taiwan. Build Environ. 2014; 72:232-42.

4. USGBC. New Construction Reference Guide Version 2.2. $2^{\text {nd }}$ ed. U.S. Green Building Council; 2006.

5. Frontczak M, Wargocki P. Literature survey on how different factors influence human comfort in indoor environments. Build Environment. 2011; 46(4):922-37.

6. Enegbuma WI, Aliagha U, Ali K. Preliminary building information modeling adoption model in Malaysia. Construction Innovation. 2014; 14(4):408-32.

7. Wargocki P, Frontczak M, Schiavon S, Goins J, Arens E, Zhang H. Satisfaction and self-estimated performance in relation to indoor environmental parameters and building features. 10th International Conference on Healthy Buildings; 2012. p. 1-7.

8. Frontczak M, Andersen RV, Wargocki P. Questionnaire survey on factors influencing comfort with indoor environmental quality in Danish housing. Build Environ. 2012; 50:56-64.

9. Frontczak M, Schiavon S, Goins J, Arens E, Zhang H, Wargocki P. Quantitative relationships between occupant satisfaction and satisfaction aspects of indoor environmental quality and building design. Indoor Air. 2012; 22(2):119-31.

10. Heschong L. Daylighting in schools: An investigation into the relationship between day lighting and human performance. California Energy Commission. 1999. p. 140.

11. Heschong L. Windows and offices: A study of office worker performance and the indoor environment. California Energy Commission. 2003.

12. Hathaway W, Hargreaves J, Thompson G, Novitsky D. A study into the effects of light on children of elementary school age - A case of daylight robbery. Planning and Information Services Division. Alberta. 1992. p. 68.

13. Issa M, Rankin J, Atallah M, Chritian A. Absenteeism, performance and occupant satisfaction with the indoor environment of Green Toronto Schools. Indoor Built Environ. 2011; 20(5):511-23.

14. Webster T, Bauman F, Dickerhoff D, Lee YS. Case study of Environmental Protection Agency (EPA) Region 8 Headquarters Building. Denver, Colorado. 2008.

15. Lee YS. Comparisons of indoor air quality and thermal comfort quality between certification Levels of LEED-certified buildings in USA. Indoor Built Environ. 2011; 20:564.

16. Kline RB. Principles and practice of structural equation modeling. $4^{\text {th }}$ ed. New York: Guilford Publications; 2015.

17. Hair JF, Black WC, Babin BJ, Anderson RE. Multivariate Data Analysis. $7^{\text {th }}$ ed. Multivariate Data Analysis; 2013.

18. Enegbuma WI, Ali KN, Ologbo AC, Aliagha UG. Preliminary study impact of building information modeling use in Malaysia. IFIP Advances in Information and Communication Technology. 2014; 442:51-62.

19. Awang Z, Afthanorhan A, Asri MAM. Parametric and non parametric approach in structural equation modeling (SEM): The application of bootstrapping. Modern Applied Science. 2015; 9(9):58-67.

20. Enegbuma WI. Factors affecting building information modeling adoption by Malaysian consultants and contractors [PhD Thesis]. University Technology Malaysia; 2016.

21. Enegbuma WI, Aliagha GU, Ali KN. Effects of perceptions on BIM adoption in Malaysian construction industry. Journal of Technology. 2015; 77(15):69-75.

22. Kamaruzzaman SN, Egbu CO, Zawawi EMA, Karim SBA, Woon CJ. Occupants' satisfaction toward building environmental quality: Structural equation modeling approach. Environmental Monitoring Assessment. 2015; 187(5):1-4. 